\title{
NAS TRILHAS DE UM PENSAMENTO COMPLEXO SOBRE RELAÇÕES DE GÊNERO E A PSICOLOGIA SOCIAL NO COTIDIANO: HOMENAGEM PARA KARIN ELLEN VON SMIGAY
}

\author{
"O presente não é um passado em potência, \\ ele é o momento da escolha e da ação"
}

(Simone de Beauvoir)

A presença dos estudos de gênero no campo da Psicologia Social não é uma novidade para muitos. No entanto, histórico foi processualmente construído por mulheres, pesquisadoras e ativistas em psicologia social, que cravaram no seio do debate sobre a construção social da sociedade e dos sujeitos um elemento estruturante: os jogos e relações de poder que se inscrevem em relações de gênero.

Uma das psicólogas sociais que, sem dúvida, faz parte desta história de aproximação entre os estudos de gênero e a Psicologia Social é Karin Ellen von Smigay. Karin foi professora da Universidade Federal de Minas Gerais (UFMG) por muitos anos, com participação ativa e determinada na existência e ampliação da Associação Brasileira de Psicologia Social (ABRAPSO), a partir de sua inserção na Regional Minas. Pesquisadora-ativista feminista e estudiosa das relações de violência de gênero, tinha como foco as tensões entre as normas de gênero e o exercício democrático do prazer e da sexualidade, sempre focalizado a partir da perspectiva dos sujeitos coletivos e suas particulares atualizações.

Karin Smigay foi uma das primeiras integrantes da ABRAPSO, quando esta ainda se caracterizava como um pequeno grupo de desbravadores que, em uníssono, apostava na revolução no meio científico com as inovações que se conseguia produzir, à época, de maneira informal. Ela era cercada por feministas que se indagavam questões de gênero que apenas começavam a aguçar o horizonte de poucos. Sua presteza, doçura e firmeza em responder ou provocar inquietações era admirável, sempre solícita aos que se aproximavam. Foi Segunda Secretária (1987-1989) e Vice-Presidente (1996-1997) da Diretoria da ABRAPSO e da comissão organizadora de diversos eventos desta entidade.

Seu caminho foi muito expressivo desde o início de sua carreira na Psicologia. Nos anos de 1980, Karin Smigay fez seu mestrado na própria UFMG, discutindo o aborto a partir dos homens: um estudo feminista pioneiro, ao apostar na radicalidade da dimensão relacional do conceito de gênero e ao trazer à cena os homens para o campo do debate sobre direitos sexuais e reprodutivos.
Como conseqüência, a autora pressupunha uma perspectiva antiessencialista do entendimento das formas de violência nas relações afetivas, buscando entendê-las como jogos de poder. Para ela, a violência de gênero é um processo complexo e sua inteligibilidade aponta para uma complicada dinâmica relacional na esfera cotidiana.

O caminho de encontro entre os estudos de gênero e a Psicologia Social parece ter permitido a autora articular um modo de compreensão das relações de violência nas relações afetivas, sexuais e amorosas, além de incrementar uma preocupação fundante da própria psicologia social brasileira: a indissociável relação entre pesquisar e intervir. Karin Smigay, ao pesquisar as relações de gênero, não dirimiu a complexidade que as relações afetivas e sexuais instalam, pelo contrario, introduziu categorias de compreensão das relações sociais na interface entre erotismo e violência. Entendia que a violência era uma forma de vínculo estruturante das relações amorosas e sexuais, permitindo elucidar os ciclos relacionais de violências de gênero e suas formas de erotização das relações. Tal leitura certamente provocou e ainda provoca resistências naqueles/as que não percebem o valor revolucionário desta abordagem.

Além disso, Karin Smigay preocupou-se com as incidências institucionais que inscrevem formas de intervenção sobre violências de gênero, ou seja, perseguiu insistentemente na preocupação sobre como as instituições públicas poderiam lidar com um mundo sensível das relações afetivas sem engessá-las em modelos simplistas de compreensão. Foi talvez este desejo que fez da feminista-pesquisadora uma deliciosa lutadora pelo funcionamento das instituições públicas que marcam o estado de direito das democracias. Ao mesmo tempo, desconfiando da capacidade das mesmas instituições, narrava a necessidade da emergência de sujeitos políticos a partir das posições feministas. Ela mesma foi um sujeito político feminista que brindou a organização de uma rede de serviços contra as violências impostas na legitimação das normas de gênero e seus efeitos perversos. Como feminista, Karin Smigay articulou o ativismo com a ciência antes mesmo de ter 
que se explicar e, talvez neste ponto, esteve seu apego institucional com a ABRAPSO e a psicologia social, pois, por meio destas, ela propunha a compreensão política das relações cotidianas e afetivas, mesmo que violentas, tendo por base a interface sujeito-sociedade e a leitura crítica das verdades instituídas

Neste sentido seu trabalho foi muito inovador, já que a visada complexa permitiu que ela compreendesse que os modelos e as formas de interpretação das violências de gênero determinam sobremaneira as possíveis consequências institucionais da intervenção. Assim, ela não ignorou os problemas da realidade, cedendo ao pensamento muitas vezes simplista e reducionista de parte da produção acadêmica. Ao contrário, ela insistiu em não abandonar a sistematização e o rigor acadêmico, tomando-as como um antídoto ao contentamento das rápidas respostas das instituições públicas. Não por outro motivo, Karin Smigay estudou durante anos as delegacias da mulher e expandiu sua compreensão da violência para o âmbito do erótico e dos ciclos relacionais como estratégia de buscar respostas mais complexas para um problema multifacetado tal como a violência.

Entre 2000 e 2001, a pesquisadora terminou seu doutorado, quando investigou as relações violentas entre casais heterossexuais, buscando compreender a complexidade da participação na cena de violência e das posições subjetivas de gênero que a implicam. Criou um modelo de entendimento enfático na idéia de que teríamos que desmistificar a violência para enfrentá-la. Ou seja, em seu doutoramento, Karin Smigay transformou as relações de intimidade em um palco de lutas, tensionando sempre o erotismo, a violência e a emancipação de gênero. Tomou a psicologia social como base para narrar a intimidade como campo da política e da democratização das relações de poder entre homens e mulheres.

Mas, a autora feminista e psicóloga social também era habilidosa em contar histórias. Guardava histórias da roça e de diferentes culturas para um dia construir sua própria narrativa dos pedaços das vidas cotidianas. Karin Smigay se interessava pelo cotidiano miúdo e como ele sustentava formas de afeto e violência e de inteligibilidade destas relações, muitas vezes, desapercebidas. Ela narrava e se interessava pela história de vida de todos e todas, colecionava narrativas que permitissem um passo a mais na compreensão da democracia da intimidade.

Seu percurso inspirou muitos estudantes de graduação e pós-graduação em diferentes estados brasileiros e por nós é aqui lembrado como uma trajetória que se encontra e desencontra com a própria Psicologia e a Sociedade. Ele se mantinha na tensão entre o afastamento e o apego para, talvez, melhor visualizar uma compreensão menos moral das relações afetivas e sexuais do mundo contemporâneo.
Nossa homenagem segue na materialidade que ela mesma buscou ao não ceder às grandes utopias. Sonhava com as mudanças do cotidiano, as pequenas que sustentam os pilares da democracia entre nós.

Sob esta ótica, não é de se estranhar que, após se aposentar da UFMG, Karin Smigay migra e monta uma pousada no interior de Minas Gerais, absolutamente sedutora e rica em detalhes voltados ao cuidado do outro - ao hóspede - que acolhido em sua casa, delicia-se com suas histórias em meio a objetos esteticamente posicionados.

Quem teve o privilégio de com ela compartilhar seu afeto e suas múltiplas histórias, as que gostava de contar e as que gostava de ouvir, compreendeu que ela proporcionava uma atmosfera acolhedora de bons encontros, gerando a alegria nas relações dialógicas que nos aumentam a potência de agir.

Sua pousada, assim como suas histórias, era construída por fragmentos de objetos, materiais de demolição, originais do século XIX, recolhidos das fazendas de Minas Gerais. Cerâmicas, produzidas e criadas por ela, estetizam o lugar e cativavam os sujeitos que circulavam pelos seus corredores, salas, uma maravilhosa biblioteca e os quartos acolhedores singularizados por poesias específicas.

A culinária, exercício do cuidado com o outro, foi tema de um de seus projetos de pesquisa intitulado "Resgate e Preservação do Patrimônio Imaterial", no qual a culinária das mulheres de Tiradentes foi trazida para a prática cotidiana e pública, em um festival de gastronomia de impacto nacional.

Sua produção, portanto, transcende o espaço acadêmico e se pauta no ativismo no campo da política da intimidade. O cuidado com o outro se fez marca da sua existência. Falamos do cuidado com o outro em múltiplos sentidos, cuja última obra, a Pousada d'Oleo de Guignard, representa o laço que une acolher, cuidar e emprestar olhos de beleza aos que dela se aproximavam.

Karin Smigay faleu dia 12 de fevereiro deste ano. Fica para nós a sensação da força e longevidade de uma vida que não se esgota no que foi, mas nos efeitos que produziu: a boa memória de uma bela pessoa que viveu intensamente sua vida e transformou a vida de muitos. Que todas as suas qualidades nos ensinem e nos ajudem a viver e a fazer do mundo um lugar melhor.

Deixamos aqui algumas produções de sua autoria publicadas na revista Psicologia \& Sociedade

- $\quad$ Smigay, Karin E. von. (1987) Delegacias de Mulheres. Psicologia \& Sociedade, 3 (3), 34-37.

- Smigay, Karin E. von. (1988) A constituição de um grupo por e para mulheres na instituição universitária: desventuras de quem a vive. Psicologia \& Sociedade, 3 (5), 103-113. 
- Smigay, Karin E. von. (1988) Itinerários da Violência Contra a Mulher ou: o que dizer da sedução? Psicologia \& Sociedade, 3 (6), 130-140.

- $\quad$ Smigay, Karin E. von. (1989) Mulheres: (re) partidas e excluídas. Psicologia \& Sociedade, 4 (7), 11-18.

- Smigay, Karin E. von. (1991) Acerca de imagens de pai. Psicologia \& Sociedade, 6 (9), 88-94.
- Smigay, Karin E. von. (1992) Acerca de Imagens do Pai: notas para pensar a paternidade no imaginário masculino. Psicologia \& Sociedade, 7 (10), 84-97.

- SMIGAY, Karin. E. von. (1999) Violação de corpos: O estupro como estratégia em tempos de guerra. Uma questão para a psicologia social? Psicologia \& Sociedade, 11 (1), 104-120.

Marco Aurélio Máximo Prado, Kátia Maheirie, Benedito Medrado e Angela Caniato 